\title{
Phases of decompensation during acute ischemia demonstrated in an ex vivo porcine bladder model
}

\author{
Natalie R. Swavely ${ }^{1}$, Zachary E. Cullingsworth ${ }^{2}$, Naveen Nandanan ${ }^{1}$, John E. Speich ${ }^{2}$, Adam P. Klausner ${ }^{1}$ \\ ${ }^{1}$ Department of Surgery/Division of Urology, Virginia Commonwealth University School of Medicine, Richmond, VA, USA; ${ }^{2}$ Department of \\ Mechanical Nuclear Engineering, Virginia Commonwealth University School of Engineering, Richmond, VA, USA \\ Contributions: (I) Conception and design: All authors; (II) Administrative support: All authors; (III) Provision of study materials or patients: All \\ authors; (IV) Collection and assembly of data: All authors; (V) Data analysis and interpretation: All authors; (VI) Manuscript writing: All authors; (VII) \\ Final approval of manuscript: All authors. \\ Correspondence to: Adam P. Klausner, MD. Division of Urology, VCU Medical Center, Box 980118, Richmond, VA 23298-0118, USA. \\ Email: adam.klausner@vcuhealth.org.
}

Background: The aim of this project was to develop an ex-vivo porcine bladder model to test the effects of increasing durations of acute ischemia on detrusor function.

Methods: Porcine bladders were perfused through bilateral vesical arteries at physiologic flow ( $4 \mathrm{~mL} / \mathrm{min}$ ) and filled through a urethral catheter. Intravesical pressures were continuously recorded using standard urodynamics equipment. Bladder contractions, with simulated voiding, were induced by arterial infusion of $\mathrm{KCl}$ at $250 \mathrm{~mL}$. Total, passive, and active pressures were recorded for each contraction and data were normalized to the control fill. Bladders underwent the following perfusion protocol by adjusting the arterial flow rates: Equilibration $(4 \mathrm{~mL} / \mathrm{min})$, control $(4 \mathrm{~mL} / \mathrm{min})$, partial ischemia $(2 \mathrm{~mL} / \mathrm{min})$, global ischemia $(0 \mathrm{~mL} / \mathrm{min})$ and reperfusion $(4 \mathrm{~mL} / \mathrm{min})$. Perfusion periods were held for $15 \mathrm{~min}$ for one group and $30 \mathrm{~min}$ for another group of bladders.

Results: Porcine bladders ( $\mathrm{N}=19)$ including 8 (15 min group) and 11 (30 min group) were used. With 15 min ischemia, passive pressure increased $39 \%(\mathrm{P}=0.03)$ and the active pressure decreased $23 \%(\mathrm{P}=0.002)$. Total pressure remained constant, identifying a compensated phase. Values returned to baseline with reperfusion. With $30 \mathrm{~min}$ ischemia, passive pressure remained unchanged. However, there was a decrease in total pressure 34\% $(\mathrm{P}<0.001)$ and active pressure 61\% $(\mathrm{P}<0.001)$, which incompletely recovered to baseline values, identifying a decompensated phase with incomplete recovery upon reperfusion.

Conclusion: In the porcine bladder, $15 \mathrm{~min}$ ischemia resulted in a compensated phase and $30 \mathrm{~min}$ ischemia resulted in a decompensated phase of detrusor function. This study provides mechanistic insight into the natural history of ischemia-mediated voiding dysfunction.

Keywords: Animal model; bladder; ischemia; muscle contraction

Submitted Feb 27, 2020. Accepted for publication Sep 10, 2020.

doi: 10.21037/tau-20-669

View this article at: http://dx.doi.org/10.21037/tau-20-669

\section{Introduction}

Chronic bladder ischemia is a potential risk factor for the development of lower urinary tract symptoms (LUTS) and has been associated with co-existing cardiovascular disease and cardiovascular disease risk factors (1-3). A meta-analysis by Gacci $e t a l$. concluded that men with moderate to severe
LUTS are at increased risk of having a major cardiac event (4). Because of this association, investigators have examined the role of chronic pelvic ischemia in the development of LUTS in both pre-clinical and clinical studies $(5,6)$.

Indeed, studies of pelvic ischemia have led to a new 


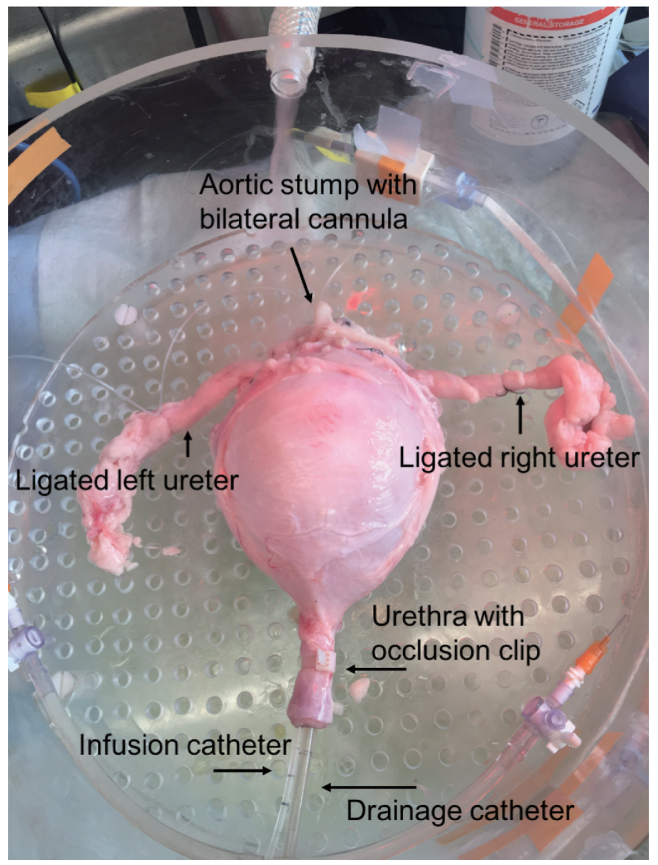

Figure 1 Ex vivo porcine bladder in custom built heated chamber with bilateral superior vesical arteries cannulated via aortic stump to allow for perfusion of oxygenated, heated KH. Bilateral ureters are suture ligated. Infusion catheter and drainage catheter secured in place with occlusion clip which also prevents leakage of bladder volume during the experiment.

understanding of a possible etiology of LUTS and have identified novel treatment targets (7-13). However, a recent review focuses on the lack of mechanistic treatments as current therapies are mainly focused on improving symptoms, rather than addressing the underlying pathophysiology (14). In this regard, a mechanistic proposal postulates that pelvic ischemia leads to progressive deterioration of detrusor muscle function, presenting initially as detrusor overactivity (DO) and ultimately leading to detrusor underactivity (DU) (15-18).

However, because chronic ischemia may lead to irreversible structural damage to the detrusor muscle, there is a pressing need to study the pathophysiology of acute ischemia to identify reversible points where potential interventions could restore both structure and function. This is especially true because of the strong association of LUTS with other comorbid conditions including erectile dysfunction, anxiety, depression, as well as the financial and personal burdens that come with a lifetime of symptom management (14).
Therefore, the aim of this project was to develop an $e x$ vivo porcine model to help define the duration of acute ischemia leading to measurable changes in bladder function and determine at what points those changes are still reversible with the restoration in flow.

We present the following article in accordance with the ARRIVE reporting checklist (available at http://dx.doi. org/10.21037/tau-20-669).

\section{Methods}

All porcine bladders and tissue utilized in these experiments were obtained from local abattoirs and do not require approval by the institutional animal care as they are not laboratory animals.

\section{Bladder harvest and preparation}

Porcine bladders were obtained from local abattoirs. As previously described, immediately after slaughter, the entire urinary tract and vasculature was removed en bloc, from kidneys to urethra, and cold perfused with Heparinized Krebs Henseleit (KH) solution (19). After removal of the kidneys and excess tissue, the ureters, bladder, urethra and vasculature were then placed into a physiologic solution, 3-(N-morpholino) propanesulfonic acid (MOPS) based buffer and transported on ice to the lab for use within 48 hours. Bilateral superior vesical arteries were identified, cannulated with polyethylene cannulas, and secured with 2-0 silk ties (Figure 1). Branching vessels and both ureters were suture ligated to limit perfusate leakage (Figure 1). A $16 \mathrm{Fr}$ drainage catheter and a $7 \mathrm{Fr}$ T-DOC ${ }^{\circledR}$ single sensor air charged bladder catheter (for filling and intravesical pressure monitoring, Laborie Inc., Mississauga, Ontario) were placed into the urethra (Figure 1). The filling catheter was connected to an Aquarius TT urodynamics system (Laborie Inc., Mississauga, Ontario) for infusion and pressure monitoring. The catheters were secured with an occlusion clip that prevented leakage. A catheter plug was placed into the $16 \mathrm{Fr}$ catheter to prevent drainage until desired.

\section{Isolated bladder set-up and perfusion}

As previously described, isolated bladders were placed into a customized heated, humified chamber to replicate physiologic conditions (19-22). Perfusate was administered 
through bilateral vesical arteries via an in-line Transpac IV pressure transducer (ICU Medical, Clemente, CA) with flow monitored by an in-line ultrasonic flowmeter (IUF-1000, Radnoti LLC, Covina, CA). The KH buffer was gassed with $95 \% / 5 \% \mathrm{O}_{2} / \mathrm{CO}_{2}$. The Aquarius TT was used for data acquisition with intravesical infusion set at $50 \mathrm{~mL} / \mathrm{min}$ for all fills, and all fills were to a volume of $250 \mathrm{~mL}$. Following fills, bladders were actively voided via a contraction induced by infusion of $50 \mathrm{~mL}$ of potassium-enriched $(110 \mathrm{mM} \mathrm{KCl})$ solution via the bilateral super vesical cannulas at a rate of $25 \mathrm{~mL} / \mathrm{min}$ and flushed with $50 \mathrm{~mL}$ of $\mathrm{KH}$ at a rate of $25 \mathrm{~mL} / \mathrm{min}$ using a programmable infusion pump (Harvard Apparatus, Holliston, Massachusetts). Each contraction was induced isovolumetrically until peak pressure was achieved after $\sim 2$ min, and then the bladder was emptied by releasing the drainage catheter plug to simulate voiding.

\section{Ischemia protocol}

Bladders were placed in the humidified chamber (Figure 1) and perfused bilaterally with warm, oxygenated $\mathrm{KH}$ buffer at $4 \mathrm{~mL} / \mathrm{min}$ for 15 minutes, as in previous studies $(19,21)$. Then two pre-experiment fill-empty cycles were performed to equilibrate the bladders and ensure viability. Following the first pre-experiment fill, the bladder was passively drained, and following the second pre-experiment fill, the bladder was actively voided via an induced contraction as previously described (19). Bladders were then subjected to four consecutive fill-active void cycles with varying degrees of ischemia as follows: Fill $1-$ control $(4 \mathrm{~mL} / \mathrm{min})$, Fill 2-partial ischemia ( $2 \mathrm{~mL} / \mathrm{min})$, Fill 3-global ischemia $(0 \mathrm{~mL} / \mathrm{min})$ and Fill 4 -reperfusion $(4 \mathrm{~mL} / \mathrm{min})$. An isovolumetric wait period was included between the end of filling and the induction of the voiding contraction. In one group of bladders, the degrees of ischemia were held for 15 minutes (15 min group) and in another group the degrees of ischemia were held for 30 minutes $(30 \mathrm{~min}$ group).

\section{Pressure data collection}

For each contraction during the urodynamics ischemia protocol, passive pressure was measured at the end of the wait period immediately before the contraction, and the peak total pressure was measured during the contraction. Active pressure was calculated as the difference between the total and passive pressures. Pressure data from all fills were normalized to the control fill, as the perfusion rate of $4 \mathrm{~mL} / \mathrm{min}$ fill approximates physiologic perfusion. Pressure values were normalized by calculating the ratio of each passive, total and active to the value of the control fill.

\section{Statistical analysis}

Two-tailed paired Student's $t$-tests were used to compare normalized pressure values, and a $\mathrm{P}$ value of $<0.05$ denotes statistical significance.

\section{Results}

A total of 19 bladders were used including 8 bladders for the 15 -minute ischemia protocol and 11 bladders for the 30 -minute ischemia protocol. This included 6 male pigs and 2 female pigs in the 15 -minute group and 6 male pigs and 5 female pigs in the 30-minute group. All pigs were of mixed breed, with main breed percentages from Yorkshire, Hampshire, Duroc, and Guinea Hog breeds. All pigs weighed between 215-375 lbs. prior to slaughter, with a mean weight of $340 \mathrm{lbs}$.

\section{5-minute ischemia protocol (Figures 2,3)}

In the 15-minute ischemia protocol (Figures $2 A, 3 A$ ), the normalized passive pressure increased by $21 \%$ with partial ischemia $(\mathrm{P}=0.02)$ and $39 \%$ with global ischemia and returned to baseline during reperfusion (112\% recovery, $\mathrm{P}=0.20)$. Normalized active pressure decreased by $11 \%$ during partial ischemia $(\mathrm{P}=0.03)$ and $23 \%$ with global ischemia $(\mathrm{P}=0.02)$, and returned to baseline during reperfusion ( $102 \%$ recovery) $(\mathrm{P}=0.73)$. However, normalized total pressure remained unchanged throughout partial ischemia, global ischemia, and reperfusion $(\mathrm{P}>0.05)$.

\section{0-minute ischemia time (Figures 2,3)}

In the 30-minute ischemia protocol (Figures $2 B, 3 B$ ), the normalized passive pressure remained unchanged throughout partial ischemia, global ischemia, and reperfusion $(\mathrm{P}>0.05)$. However, the normalized active pressure decreased by $30 \%$ with partial ischemia $(\mathrm{P}<0.001)$ and $61 \%$ with global ischemia $(\mathrm{P}<0.001)$ and demonstrated only a partial recovery of $72 \%$ during reperfusion $(\mathrm{P}=0.02)$. The normalized total pressure decreased by $18 \%$ with partial ischemia $(\mathrm{P}<0.001)$ and decreased $34 \%$ with global 


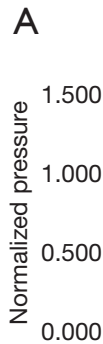

B

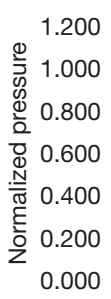

15-minute ischemia group

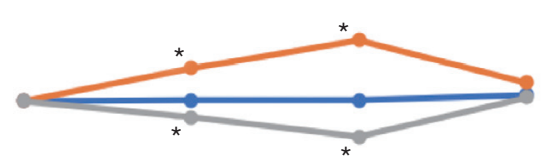

Control Partial ischemia Global ischemia Reperfusion

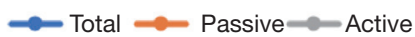

30-minute ischemia group

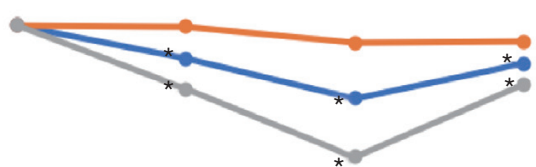

Control Partial ischemia Global ischemia Reperfusion

$\leadsto$ Total $\leadsto$ Passive $\leadsto$ Active

Figure 2 Normalized total (blue line), passive (orange line) and active (grey line) pressures during physiologic perfusion, control (4 mL/min), partial ischemia $(2 \mathrm{~mL} / \mathrm{min})$, global ischemia $(0 \mathrm{~mL} / \mathrm{min})$, and reperfusion $(4 \mathrm{~mL} / \mathrm{min})$. Time periods were held for $15 \mathrm{~min}(\mathrm{~A})$ and $30 \mathrm{~min}(\mathrm{~B}) .{ }^{*}, \mathrm{P}<0.05$.

ischemia $(\mathrm{P}<0.001)$ and demonstrated partial recovery to $82 \%(\mathrm{P}=0.36)$.

\section{Discussion}

The key findings of this investigation were that, in the perfused whole porcine bladder, the duration and degree of acute ischemia affects the detrusor contractile function in different ways. Specifically, a shorter duration of ischemia (15 min) leads to an increase in passive pressure and a corresponding decrease in active pressure. The result is that total pressure is unchanged and can be viewed as a compensated phase. In contrast, a longer duration of ischemia (30 min) leads to decreases in both passive and active pressure. The result is that total pressure drops and can be viewed as a decompensated phase. These findings are consistent with the hypothesis that ischemia-induced voiding dysfunction may be a progressive phenomenon, where partial or short-duration ischemia can increase detrusor muscle stiffness (i.e., increase passive pressure) leading to compensated voiding, but with increased LUTS, as has been demonstrated in rat models $(16,23)$. Then, as the duration or severity of ischemia progresses, this compensatory mechanism may fail, resulting in underactive bladder (UAB).

One mechanistic explanation for ischemia-induced voiding dysfunction is that decreased blood flow can lead to detrusor muscle damage through the generation of reactive oxygen species (ROS). In a study by Kirpatovsky et al., four hours of acute urinary retention was induced in rats. Examination of bladders immediately and 24 hours after retention demonstrated reduced blood flow with increased levels of ROS in the muscle and mucosa which persisted through the study. This increase in ROS paralleled changes in urinary symptoms with a significant increase in the frequency and amplitude of spontaneous contractions as well as detrusor tone. Likewise, in bladder strips, the effects of acute urinary retention manifested as significantly decreased contractile force (24). Additionally, acute ischemia in detrusor strips has been shown to increase the tone of the detrusor muscle, which is reversed with reperfusion. Interestingly, this increase in muscle tone was shown to be blocked with anticholinergics, which has been theorized to suggest a relationship between acute ischemia and increase local acetylcholine release (25).

At the cellular and genetic levels, the effect of ischemia has been examined by inducing acute unilateral ischemia in the rabbit bladder at time periods ranging from 1 hour to 7 days. Changes were identified on both the ischemic and non-ischemic sides of the bladder, with increased alterations seen on the ischemic side. These changes, including DNA synthesis, protein synthesis, and increased expression of early response genes such as c-fos and c-jun were similar to those observed after outlet obstruction and bladder overdistention (26). In vivo, two hours of bilateral pelvic ischemia in a rabbit bladder showed a significant decrease in contractile responses with alterations in Rho-kinase and smooth muscle regulatory proteins which further decreased after reperfusion (27). These results were in agreement with an older study investigating the effects of 1 hour of bilateral ischemia in the rabbit bladder, which showed a $48 \%$ reduction in contraction force (28).

Increasingly, porcine models are being used as a model to examine human physiology. This has been seen most well known in cardiac models, but has also been used in gastrointestinal models as well as pulmonary models (29-33). Recently this model has been used in the Urologic world to model bladder physiology and to be better understand 
A

15-minute ischemia group

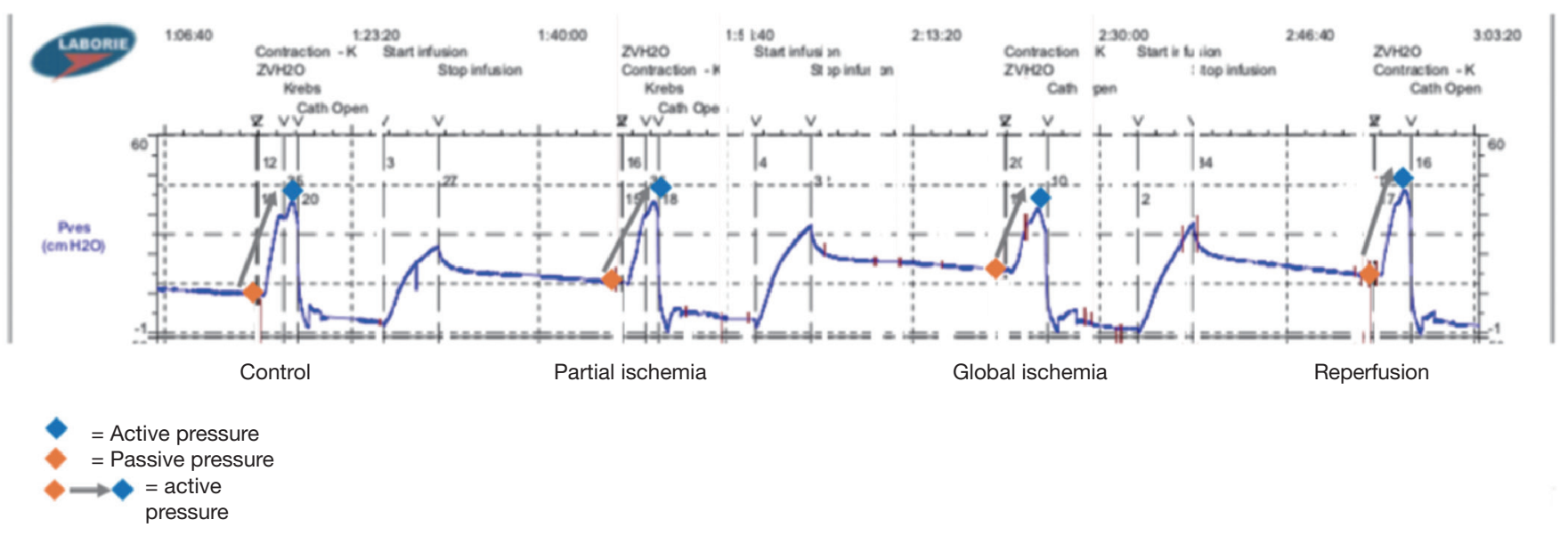

B

30-minute ischemia group

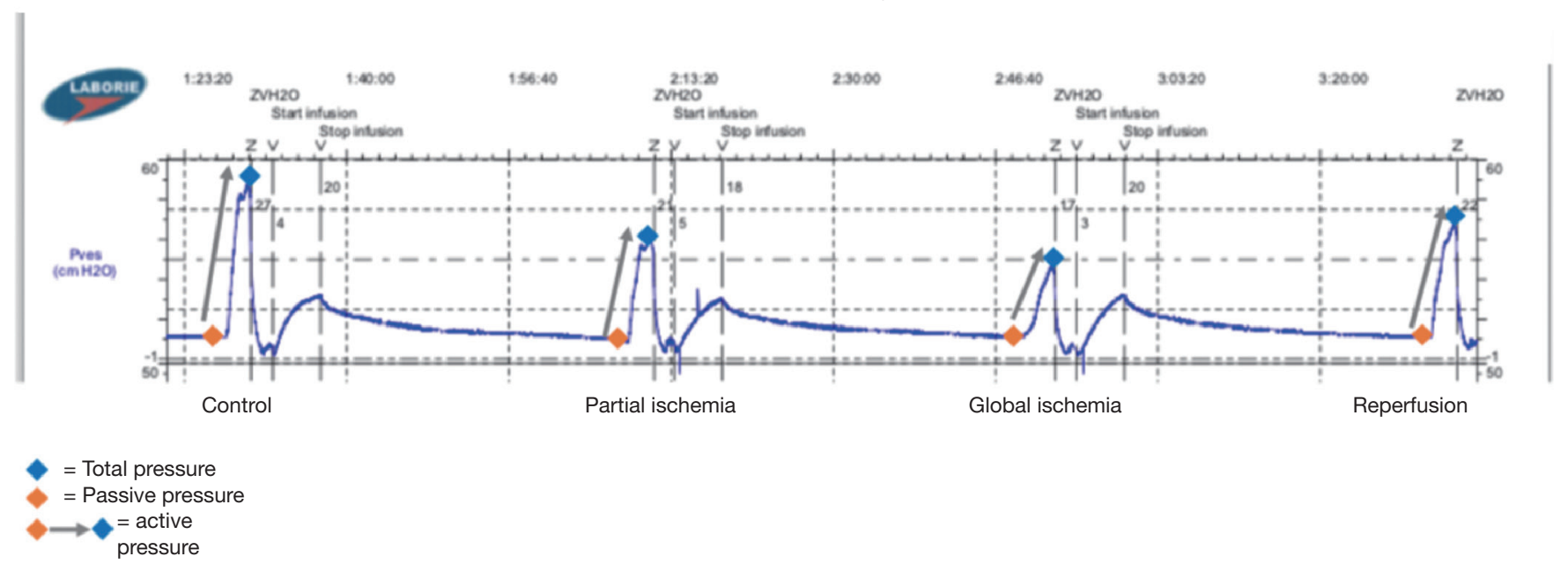

Figure 3 Urodynamics tracing of (A) 15-minute ischemia time. The rise in passive pressure is demonstrated with the decrease in active pressure and the maintenance of total pressure. The passive and active pressures return to baseline with reperfusion. Urodynamics training of (B) 30-minute ischemia time. The passive pressure remains constant while the active pressure and total pressure decrease. The active pressure and total pressure make an incomplete recovery with reperfusion.

pathology (19-21,25,34,35). In previous porcine strip studies, it has been shown that the lamina propria also contracts, in conjunction with the detrusor muscle. The urothelium and lamina propria respond to prostaglandins, like the detrusor muscle, as well as serotonin $(34,35)$. This model measured the total contraction, without examining the exact contribution of detrusor vs. lamina propria or urothelium, however the majority of the contract is sustained by the detrusor.

Limitations of the current study include the relatively small sample size, use of male and female pigs, and the recognition that in vitro porcine bladders may not faithfully represent the human condition. These bladders were obtained from two abattoirs, so there could be some variability in the pig diet prior to slaughter. However, all bladders were harvested by study authors immediately after slaughter in order to standardize handling and experimentation. In addition, the bladders were perused with $\mathrm{KH}$ solution, which may not have the same effects as whole blood. Bladders were used between 24-48 hours 
after harvest. The time variability may be a confounding factor. To account for this, all bladders underwent two prestudy fill-void cycles to ensure the baseline contractility of the bladder is at the same magnitude as previously used bladders. However, the porcine bladder model represents an excellent approximation of the human bladder with easy ability to manipulate vascular inflow, and the results demonstrate a mechanistic progression from a compensated, overactive phase of acute ischemia to a decompensated, underactive phase of acute ischemia.

\section{Conclusions}

A whole porcine bladder model demonstrated different phases of decompensation during acute ischemia. With 15 minutes of ischemia, there is a compensated overactive phase where increases in passive pressure are offset by decreases in active pressure. However, with progression to 30 minutes of acute ischemia, there is a decompensated $\mathrm{UAB}$ phase where both passive and active pressures are decreased. This model provides a mechanistic explanation for the theoretical progression from overactive to $\mathrm{UAB}$ and provides rational targets for the study of future therapies aimed at ischemia-mediated voiding dysfunction.

\section{Acknowledgments}

We would like to acknowledge David Burk of Burk's Farm and Mike Silver of Silver Ridge Farm for facilitating bladder procurement, Dr. Martin Mangino for assistance in the laboratory setup, and College of Engineering students Sydney Roberts and Ryan Musselman for assistance with experimental protocols.

Funding: None.

\section{Footnote}

Reporting Checklist: The authors have completed the ARRIVE reporting checklist. Available at http://dx.doi. org/10.21037/tau-20-669

Data Sharing Statement: Available at http://dx.doi. org/10.21037/tau-20-669

Peer Review File: Available at http://dx.doi.org/10.21037/ tau-20-669

Conflicts of Interest: All authors have completed the ICMJE uniform disclosure form (available at http://dx.doi. org/10.21037/tau-20-669). The authors have no conflicts of interest to declare.

Ethical Statement: The authors are accountable for all aspects of the work in ensuring that questions related to the accuracy or integrity of any part of the work are appropriately investigated and resolved. All porcine bladders and tissue utilized in these experiments were obtained from local abattoirs and do not require approval by the institutional animal care as they are not laboratory animals.

Open Access Statement: This is an Open Access article distributed in accordance with the Creative Commons Attribution-NonCommercial-NoDerivs 4.0 International License (CC BY-NC-ND 4.0), which permits the noncommercial replication and distribution of the article with the strict proviso that no changes or edits are made and the original work is properly cited (including links to both the formal publication through the relevant DOI and the license). See: https://creativecommons.org/licenses/by-nc-nd/4.0/.

\section{References}

1. Ponholzer A, Temml C, Wehrberger C, et al. The Association Between Vascular Risk Factors and Lower Urinary Tract Symptoms in Both Sexes. Eur Urol 2006;50:581-6.

2. Thurmond P, Yang JH, Azadzoi KM. LUTS in pelvic ischemia: a new concept in voiding dysfunction. Am J Physiol Renal Physiol 2016;310:F738-F743.

3. Lin WY, Andersson KE, Lin CL, et al. Association of lower urinary tract syndrome with peripheral arterial occlusive disease. PLoS One 2017;12:e170288.

4. Gacci M, Corona G, Sebastianelli A, et al. Male lower urinary tract symptoms and cardiovascular events: a systematic review and meta-analysis. Eur Urol 2016;70:788-96.

5. Camões J, Coelho A, Castro-Diaz D, et al. Lower urinary tract symptoms and aging: the impact of chronic bladder ischemia on overactive bladder syndrome. Urol Int 2015;95:373-9.

6. Yamaguchi $\mathrm{O}$, Nomiya $M$, Andersson KE. Functional consequences of chronic bladder ischemia. Neurourol Urodyn 2014;33:54-8.

7. Goi Y, Tomiyama Y, Nomiya M, et al. Effects of silodosin, a selective $\alpha 1 \mathrm{~A}$-adrenoceptor antagonist, on bladder blood flow and bladder function in a rat model of atherosclerosis 
induced chronic bladder ischemia without bladder outlet obstruction. J Urol 2013;190:1116-22.

8. Goi Y, Tomiyama Y, Maruyama I, et al. Silodosin, an $\alpha 1 \mathrm{~A}$-adrenoceptor antagonist, may ameliorate ischemiainduced bladder denervation and detrusor dysfunction by improving bladder blood flow. Pharmacology 2016;97:161-70.

9. Shim JS, Bae JH. Drug Concentration in Rat Plasma, Bladder, and Prostate after Mirodenafil Administration in a Chronic Pelvic Ischemia Model. Urology 2016;91:244.e1-5.

10. Sawada N, Nomiya M, Hood B, et al. Protective effect of a $\beta 3$-adrenoceptor agonist on bladder function in a rat model of chronic bladder ischemia. Eur Urol 2013;64:664-71.

11. Nomiya M, Andersson KE, Yamaguchi O. Chronic bladder ischemia and oxidative stress: New pharmacotherapeutic targets for lower urinary tract symptoms. Int J Urol 2015;22:40-6.

12. Andersson KE, Boedtkjer DB, Forman A. The link between vascular dysfunction, bladder ischemia, and aging bladder dysfunction. Ther Adv Urol 2017;9:11-27.

13. Andersson KE, Nomiya M, Yamaguchi O. Chronic pelvic ischemia: Contribution to the pathogenesis of lower urinary tract symptoms (LUTS): A new target for pharmacological treatment? Low Urin Tract Symptoms 2015;7:1-8.

14. Abler LL, Vezina CM. Links between lower urinary tract symptoms, intermittent hypoxia and diabetes: Causes or cures? Respir Physiol Neurobiol 2018;256:87-96.

15. Nomiya M, Yamaguchi O, Akaihata H, et al. Progressive vascular damage may lead to bladder underactivity in rats. J Urol 2014;191:1462-9.

16. Zhao Z, Azad R, Yang JH, et al. Progressive changes in detrusor function and micturition patterns with chronic bladder ischemia. Investig Clin Urol 2016;57:249-59.

17. Sagawa K, Aikawa K, Nomiya M, et al. Impaired detrusor contractility in a rat model of chronic bladder ischemia. Urology 2013;81:1379.e9-14.

18. Zhang Q, Siroky M, Yang JH, et al. Effects of ischemia and oxidative stress on bladder purinoceptors expression. Urology 2014;84:1249.e1-7.

19. Anele UA, Ratz PH, Colhoun AF, et al. Potential vascular mechanisms in an ex vivo functional pig bladder model. Neurourol Urodyn 2018;37:2425-33.

20. Vince R, Tracey A, Deebel NA, et al. Effects of vesical and perfusion pressure on perfusate flow, and flow on vesical pressure, in the isolated perfused working pig bladder reveal a potential mechanism for the regulation of detrusor compliance. Neurourol Urodyn 2018;37:642-9.

21. Balthazar A, Cullingsworth ZE, Nandanan N, et al. An external compress-release protocol induces dynamic elasticity in the porcine bladder: A novel technique for the treatment of overactive bladder? Neurourol Urodyn 2019;38:1222-8.

22. Parsons BA, Drake MJ, Gammie A, et al. The validation of a functional, isolated pig bladder model for physiological experimentation. Front Pharmacol 2012;3:52.

23. Azadzoi KM, Tarcan T, Kozlowski R, et al. Overactivity and structural changes in the chronically ischemic bladder. J Urol 1999;162:1768-78.

24. Kirpatovsky VI, Plotnikov EY, Mudraya IS, et al. Role of oxidative stress and mitochondria in onset of urinary bladder dysfunction under acute urine retention. Biochemistry (Mosc) 2013;78:542-8.

25. Tracey AT, Anele UA, Vince RA, et al. Bladder attack: Transient bladder ischemia leads to a reversible decrease in detrusor compliance. Transl Androl Urol 2019;8:703-11.

26. Chen MW, Buttyan R, Levin RM. Genetic and cellular response to unilateral ischemia of the rabbit urinary bladder. J Urol 1996;155:732-7.

27. Juan YS, Li S, Levin RM, et al. The Effect of Ischemia/ Reperfusion on Rabbit Bladder-Role of Rho-kinase and Smooth Muscle Regulatory Proteins. Urology 2009;73:1126-30.

28. Vanarsdalen KN, Wein AJ, Levin RM. The contractile and metabolic effects of acute ischemia on the rabbit urinary bladder. J Urol 1983;130:180-2.

29. Møller-Helgestad OK, Ravn HB, Møller JE. Large porcine model of profound acute ischemic cardiogenic shock. Methods Mol Biol 2018;1816:343-52.

30. Manninger M, Zweiker D, van Hunnik A, et al. Arterial hypertension drives arrhythmia progression via specific structural remodeling in a porcine model of atrial fibrillation. Heart Rhythm 2018;15:1328-36.

31. Eckhouse SR, Logdon CB, Oelsen JM, et al. Reproducible porcine model of thoracic aortic aneurysm. Circulation 2013;128:S186-93.

32. Prosst RL, Schurr MO, Schostek S, et al. Porcine survival model to simulate acute upper gastrointestinal bleedings. Lab Anim 2016;50:217-20.

33. Judge EP, Hughes JM, Egan JJ, et al. Anatomy and bronchoscopy of the porcine lung. A model for translational respiratory medicine. Am J Respir Cell Mol 
Biol 2014;51:334-43.

34. Stromberga Z, Chess-Williams R, Moro C. The five primary prostaglandins stimulate contractions and phasic activity of the urinary bladder urothelium, lamina propria

Cite this article as: Swavely NR, Cullingsworth ZE, Nandanan N, Speich JE, Klausner AP. Phases of decompensation during acute ischemia demonstrated in an $e x$ vivo porcine bladder model. Transl Androl Urol 2020;9(5):21382145. doi: $10.21037 /$ tau-20-669 and detrusor. BMC Urol 2020;20:48.

35. Moro C, Edwards L, Chess-Williams R. 5-HT2A receptor enhancement of contractile activity of the porcine urothelium and lamina propria. Int J Urol 2016;23:946-51. 